\title{
Students as partners: the development of an extensive reading programme at the Ningbo Campus of the University of Nottingham
}

\author{
Peter Sturman, Yangyang Zheng, Lexiao Peng, Doran Lamb \\ University of Nottingham Ningbo, China
}

\section{Introduction}

The relationship between higher levels of extensive reading and academic, economic and social success is well established (National Endowment for the Arts, 2007). Nonetheless, extensive reading is not always valued as highly as might be expected in preliminary-year English language programmes. At the University of Nottingham Ningbo China (UNNC), students focus on reading for academic purposes. Reading for pleasure is not completely ignored, however: there have been several initiatives to promote and develop extensive reading at UNNC, such as a 'Nottingham Reading Scheme', a reading quiz, and a reading interest group (called 'Reading Circles', which, in most cases, was a tutor-led, bookdiscussion forum and open reading session). Unfortunately, these have always sat outside the mainstream structures of the University and the teaching objectives. Consequently, their success has depended on the level of commitment both of staff and of students. As Delpish et al (2010) point out, students in general are accustomed to, and often comfortable with, assuming a relatively powerless role and academics tend to feel that that their expertise gives them complete authority over learning processes. In 2016, there was a chance for a team of five students and two staff partners to redesign the Reading Circle programme completely and address the issues that the students had identified. These were: the structure and content of the programme, the lack of reward for effort and commitment and, above all, the lack of student authority over its direction and organisation. Fortunately, two members of staff were willing to engage with students as partners and the management of the Centre for English Language Education (CELE) supported change. At the same time, the University was promoting the value of 'Students as Change Agents' (SACA) and it was decided that this would be an ideal vehicle to enable the students to redesign, lead and manage Reading Circles and make it what they wanted. It would change Reading Circles from a programme dependent on a variable degree of tutor commitment into a fully studentled peer scheme for preliminary-year students, in which the student organisers (second-year students) would be rewarded by the University's Nottingham Advantage Award (NAA) system ${ }^{1}$. Cook-Sather et al. (2014) argue that close interaction between faculty and students is one of the most important factors in student learning, development, engagement and satisfaction in college - and this case study supports that position completely. As a result of this programme, the students involved were able to develop a range of skills - project management, leadership, personal and interpersonal communication - and four of them also went on to present at international conferences.

\footnotetext{
${ }^{1}$ An NAA is an additional non-academic programme that students can study outside their normal degree subject; it is aimed at enhancing student employability through a wide range of opportunities. Although these NAAs are credit bearing, they do not bear academic credits.
} 


\section{Case Studies}

\section{Why promote extensive reading at all?}

There is a phenomenon among Chinese learners of English called the 'English learning trap' in which the difficulty of English at high school leads to demotivation and lack of effort; in consequence, English becomes increasingly difficult and frustrating. Ultimately, students lose motivation and begin to resent learning English. However, when students have autonomy over the choice of content, pace of reading and organisation of a reading programme, they can focus on enjoying the content instead of worrying excessively about the difficulty of the language itself. One of the student partners argued that the motivation in such cases is intrinsic rather than extrinsic: "you're doing it because you want to, not because you have to". Furthermore, reading in English opens doors to the wider world and encourages the imagination.

From a teacher's perspective, the value of extensive reading is clear. The National Endowment for the Arts report (2007) demonstrates that, in the USA, better readers score better on writing tests, are more likely to have higher salaries, do volunteer activities and vote (op.cit., pp. 15, 17, 18 and 19, respectively). Vezzali et al. (2015, p. 105) emphasise the positive social impact of reading novels, arguing that novels "address important social, cultural, and psychological issues, such as culture, society, social inequalities, love, the transition to maturity, [and] prejudice". Gierzynsky and Eddy $(2013$, p. 6.) demonstrated that readers of the Harry Potter series were more likely "to be more accepting of those who are different, to be more politically tolerant, to be more supportive of equality, to be less authoritarian, to be more opposed to the use of violence and torture, to be less cynical, and to evince a higher level of political efficacy". It would be nice to think that the teaching of academic reading would lead to higher levels of critical thinking and to other similarly positive outcomes, but it seems that, at least for some students, reading novels is a fast track to personal development, empathy and reflection. The staff partners in this project might not share the same taste in books as each other or the students, but we have one thing in common - we love reading.

\section{Student enthusiasm; staff reluctance}

Students were concerned that the Reading Circle programme might disappear completely if the tutors were not enthusiastic; they were equally worried that teachers might well give up on it completely if there were only a few student participants. The students argued that a student-led group would be more likely to guarantee its continuing existence; even just a few truly passionate students would be willing to put the effort in to sustain and organise the programme. Moreover, it was also argued that students would have a greater sensitivity to levels of reading difficulty and student preferences than tutors. All of these were pertinent points. They also argued that the effort put into running the programme should be both recognised and rewarded. This, they maintained, would attract people willing to manage the programme and ensure a better year-by-year hand-over. Students felt turning Reading Circles into its own Nottingham Advantage Award was a good way to do this.

The staff involved had some reservations about this direction. They were concerned that the final result might reduce flexibility and become more of an administrative chore; that it might attract people who were interested only in getting the NAA credits, rather than reading for its own sake. Creating an NAA is a large and time-consuming undertaking: all the documentation is in English and there are strict deadlines to be adhered to. It was feared 


\section{Case Studies}

that students might not fully understand the staff workload implications of some of their proposals and that their initial enthusiasm for change might not be maintained in the face of all the work that would have to be done - leaving the staff partners either to complete the work or to abandon it. Once it became clear how great an undertaking this would be, two staff members, who had both initially been interested in participating in Reading Circles, dropped out very quickly and one student also flatly declined to be involved. In fact, at the very first meeting to decide whether to go ahead with this, there was too much confusion and not enough enthusiasm. The programme very nearly did not get off the ground at all.

\section{Student autonomy to create an NAA}

SACA (University of Nottingham, 2016) had been running at the UK campus for several years, but this was only the second SACA project on the China campus. Since structures to support SACA projects were still being put into place in China, the project depended on approval by, and support from, the UK team. In fact, because a SACA project is itself a Nottingham Advantage Award, the students, by doing a SACA project, would be able to get NAA credits. (However, not many students are actually aware that students in China can register for NAAs that are run from the UK campus.) The actual project would be to create a new Nottingham Advantage Award for Extensive Reading; hence students would receive SACA NAA credits for creating an Extensive Reading NAA. This had to be explained several times.

The UK SACA team provided help in two main respects: project management and transferable skills. They supported the students throughout the process by going over the 'Project Brief', helping to explain vital teamwork concepts, and giving feedback on the various components submitted as part of the process. The Project Brief is a template which includes objectives, project deliverables, scope, a risk analysis and a schedule of activities. Two of the main problems were the students' lack of experience of teamwork and their lack of a clear picture of the final product. The students had to organise work among themselves - with some of it done individually and some by teams - define outcomes, goals and deliverables and create a highly-detailed timeline. This forced the team to recognise what was necessary to complete each step and how long it might take. Regular meetings were arranged between the staff partners and the students, but the students were effectively following a programme that was already well-established through the UK SACA team and quite quickly came to know more about what they had to do (using the electronic portfolio platform Mahara, for example) than the staff partners did. Many of the training materials (teamwork skills, role recognition, survey design and ethical approval guidelines, for example) that were made available by the SACA UK team were so valuable that they became embedded in the new Extensive Reading NAA content, with the consent of the UK SACA team. The students remarked that, prior to joining this project, they had hardly ever thought about whether students could take responsibility for changes and that they had had a relatively passive and cynical attitude to the learning environment: if there was a problem, it was someone else's job to fix it - and it probably would never be fixed, so why bother? Now they realised that, through their own enthusiasm, initiative and effort, changes could be made - with results that would benefit everyone! This accords with the positions of Barnes et al. (2011) and Sambell and Graham (2011), who argue, respectively, that: student/faculty partnerships lead to students' gaining a better understanding of the university and their place 


\section{Case Studies}

within the university community; students become aware of their potential to be more active and meaningful contributors to the academic community (Cook-Sather et al., 2014, p. 102).

\section{Problems encountered}

Students quickly recognised that they were not familiar with the volume or type of work involved in developing a module and submitting a written proposal for ethical approval for the distribution of a survey. These were areas in which the staff partners were able to contribute more, as they had several years of experience of such things. Nevertheless, it was the students who, as part of their SACA programme, had ultimately to obtain the ethical approval to distribute the survey. This took much longer than expected and many amendments were needed to complete the application. The survey was finally completed very much at the last minute - just before students left for a vacation period. Many changes to the Project Brief timeline were also necessary, following feedback from the SACA team. The first version was much too simple and lacked detail; an improved version was vital to the success of the project. The students had no prior experience of reflective practice or risk assessment and, even though clear instructions were given, they were very concerned about whether what they were doing was what was expected; on many occasions, they needed support with their written English expression - and, later, with their preparation for their presentations.

Perhaps the most important problem was with the planned project itself. The students admitted that they had no real way of knowing whether it would work in the way they hoped. One of the staff partners suggested a trial run, which revealed problems that had not been anticipated. The greatest was managing continuity when the student managers of the new NAA were all absent, studying abroad - there was no-one left to manage the handover. The project now incorporates an information-sharing and hand-over session with provision for leaving mentors to keep in touch with the new ones via social media.

Also, one of the concerns raised by one of the members of staff who chose not to be involved seemed, at one point, to have been entirely valid: the students had unrealistic expectations of how many students could be enrolled in their new NAA or, more specifically, of the impact this would have on staff workload. Every NAA must have at least one Module Convenor, who is always a staff member, and every enrolled student has to create a portfolio of reflective writing in order to qualify for the NAA credits. These portfolios have to be checked by the staff tutors and there is a limit as to how many of these can reasonably be done, especially during the examination and marking periods at the end of the semester, which, of course, is when they are due.

\section{Has it worked?}

The new NAA for Extensive Reading was launched in September 2017 with eight Reading Circles, each run by a second-year student mentor. These mentors were selected through their participation in the programme in their first year of study. The benefits of it have been: the student mentors are now more willing to take responsibility for change; the number of students attending was, at least at first, higher than in the previous year when the programme had been administered by tutors. From the outside, the motivation to improve, continuously, the student experience has perhaps been most noticeable aspect. The student organisers meet regularly, exchange materials and discuss how to run their circles; there was pride in the high attendance at early meetings (though also concern over low 


\section{Case Studies}

attendance in the later ones) and the student organisers volunteered to continue in the following semester even after the credit-bearing component had finished. There is, therefore, evidence that the partnership and the final product were successful. Unfortunately, from the staff side, there is now concern about the lack of a substantive role for the tutors and the relatively low attendance rates at the later Reading Circle meetings. There are now wellintentioned voices arguing for tutors to take back responsibility for the programme and that student autonomy should not be the highest priority if the programme does not appear to be succeeding. Of course, this depends on what constitutes success and, crucially, where authority for this lies. Vanpee (2017) argues that students are in the best position to offer suggestions for improvement to curricula and programmes, as they are more likely ultimately to recognise what they need. Students should not be seen simply as recipients of the change we believe in. However, the original students are no longer involved in the scheme and, it has been argued, it was their commitment and energy that moved the process forward. The people who have subsequently taken over, or become involved, do not see it from the same perspective or have the same vision of the programme. Whilst it would be a pity if student autonomy and responsibility is reduced as a result of any new initiatives, it could be argued that the process of working towards change was more rewarding than the finished product, even though the students tried to incorporate regeneration and reflective change into the project. The student/staff partnership of this case study successfully changed a programme that previously had been criticised by students and had evidently not been working well into one that students took control over and assumed responsibility for. The intangible products of this - what the student partners learned about their own abilities may ultimately be more valuable than the finished programme itself. The students learned that they had agency, authority and responsibility. They were engaged and committed and went on to represent the University at conferences overseas. They are now ambassadors for SACA and for Extensive Reading. It was a privilege to work with them and be part of progressive change in the University.

\section{Conclusion}

One of the student partners summed up what for her was the main value of this project: "Changing Reading Circles brought more than we expected: we also changed ourselves". From a staff perspective, it was an opportunity to see how the University was able to live up to its promise to 'put students at the heart of the university' (University of Nottingham Ningbo China, 2016). To be part of the process of supporting four second-year students at UNNC to travel to the UK and Japan and give presentations at international conferences has been a remarkably positive experience. Interestingly, it has also led to more awareness of, and reflection about, the lack of appropriate procedures for sharing information about this among colleagues or for finding out about similar projects that other colleagues and students are undertaking. It is unclear, for example, whether any other students at UNNC have been involved as student partners; there appears to be no clear way to find out. Nevertheless, having a credit-bearing NAA module which was designed by students for students and managed by students - and with in-built provision for constant improvement - is an achievement for all to be proud of. 


\section{Case Studies}

\section{Reference list}

Barnes, E., Goldring, L., Bestwick, A. and Wood, J. (2011) 'A Collaborative Evaluation of Student-Staff Partnership in Inquiry-Based Educational Development.' In: Little, S. (ed.), Staff-Student Partnerships in Higher Education. London: Continuum, 16-30.

Cook-Sather, A., Bovill, C. and Felten, P. (2014) Engaging students as partners in learning and teaching: A guide for faculty. San Francisco, CA: Jossey-Bass.

Delpish, A., Holmes, A., Knight-McKenna, M., Mihans, R., Darby, A., King, K. and Felten, P. (2010) 'Equalizing Voices: Student-Faculty Partnership in Course Design.' In: Werder, C. and Otis, M.M. (eds.), Engaging Student Voices in the Study of Teaching and Learning. Sterling, VA: Stylus, 96-114.

Gierzynski, A. and Eddy, K. (2013) Harry Potter and the Millennials: Research Methods and the Politics of the Muggle Generation. Baltimore: John Hopkins University.

National Endowment for the Arts (2007) To Read or Not to Read: A Question of National Consequence. Available at: http://www.nea.gov/research/toread.pdf (Accessed: 8 December 2015).

Sambell, K. and Graham, L. (2011) 'Towards an assessment partnership model? Students' Experiences of being Engaged as Partners in Assessment for Learning (AfL) Enhancement Activity.' In: Little, S. (ed.), Staff-Student Partnerships in Higher Education. London: Continuum, 31-47.

University of Nottingham (2016) Student Opportunities: Students as Change Agents. Available at: http://www.nottingham.ac.uk/currentstudents/studentopportunities/students-aschange-agents/index.aspx (Accessed: 9 December 2016).

University of Nottingham Ningbo China (2016) Strategy 2020: A Roadmap to Success and Sustainability. Available at: http://www.nottingham.edu.cn/en/about/documents/unncstrategy-2020-english-version2.pdf (Accessed: 27 November 2017).

Vanpee, K. (2017) 'Responding to Making Change Happen: Students as Partners for Change.' The Modern Language Journal, 101, 427-430. Available at:

http://onlinelibrary.wiley.com/doi/10.1111/modl.12421/full (Accessed: 20 December 2017).

Vezzali, L., Stathi, S., Giovannini, D., Capozza, D. and Trifiletti, E. (2015) 'The greatest magic of Harry Potter: Reducing prejudice.' Journal Of Applied Social Psychology, 45, 105121. Available at: http://onlinelibrary.wiley.com/doi/10.1111/jasp.12279/full (Accessed: 20 December 2017). 